\section{Posesiones inalienables: conservación y circulación de objetos de personas desaparecidas en la Argentina y Colombia}

\author{
Ana Guglielmucci ${ }^{(1)}$
}

\begin{abstract}
Resumen: A lo largo de mi trabajo de campo en la Argentina y Colombia (2000-2020) he tenido la oportunidad de registrar distintas situaciones en las que los objetos que pertenecieron a personas desaparecidas son salvaguardados de múltiples maneras de los avatares del tiempo y el olvido. Una de estas formas de hacerlos perdurables ha sido a través de altares domésticos, prácticas forenses, performances de denuncia pública y obras artísticas. Tales objetos -entendidos como "posesiones inalienables" (Weiner, 1992)- adquieren valor a través de su preservación, archivo y exposición estética, en lugar de su intercambio en una economía de mercado o de valor simbólico. En este texto, a partir de la descripción de distintas experiencias, analizo cuáles son las prácticas orientadas a conservar la existencia de objetos que han trascendido la desaparición de sus poseedores y las formas restringidas de circularlos o exponerlos en determinadas situaciones o contextos en los que adquieren novedosas significaciones. Este análisis permite ver la manera en que tales objetos se convierten en reliquias o huellas de existencias negadas y, al mismo tiempo, en mediaciones para el reclamo político en escenarios públicos.
\end{abstract}

Palabras clave: Desaparición forzada - posesiones personales - memoria - duelo colectivo.

[Resúmenes en inglés y portugués en la página 63]

(1) Ana Guglielmucci es doctora en Antropología, investigadora adjunta del CONICET y profesora del Departamento de Antropología en la Facultad de Filosofía y Letras, Universidad de Buenos Aires. Sus estudios se focalizan en los procesos de memoria vinculados a eventos de violencia masiva en América latina. ICA/UBA (CONICET) Correo: mucciana 74@gmail.com

\title{
Introducción
}

La desaparición de un individuo o grupo en el marco de un contexto represivo o violento ya sea debido a conflictos armados, dictaduras o guerras, suele resignificar los objetos personales (fotografías, vestimenta, cartas, diarios íntimos, juguetes, entre otros) que ellos utilizaban y que les identificaban frente a los demás. Lo que antes podía ser considerado 
como una mercancía, en un mundo caracterizado por la intercambiabilidad y la obsolescencia programada de casi todas las cosas, suele transformarse en un objeto intransferible o exclusivo a raíz de la ausencia forzada de su poseedor. Algunos se guardan con recelo de las miradas ajenas, mientras que otros se vuelven elementos de altares hogareños o, circulan de maneras particulares por fuera del espacio doméstico, excluyéndoselos de la acostumbrada dinámica del intercambio comercial.

Una de estas formas de uso, circulación y exposición son las conmemoraciones o acciones colectivas que ponen en evidencia la "muerte desatendida" (Panizo, 2012) y el duelo suspendido, en las que se denuncia la desaparición frente al gobierno u otro tipo de autoridad $\mathrm{o}$ agente responsable. Por lo general, son las fotografías del documento de identidad (justamente la que fue registrada y archivada por el Estado) y, con menor frecuencia los escritos personales (cuentos, poesías, etc.), los que se exponen y circulan en este tipo de eventos. Ya sea montados en pancartas que reclaman "aparición con vida", "vivos se los llevaron, vivos los queremos", "sin olvido", “que los busquen” o "justicia para...”, o, en atriles o sillas vacías con un rostro y tal vez un nombre y la última fecha en la que esa persona fue vista con vida.
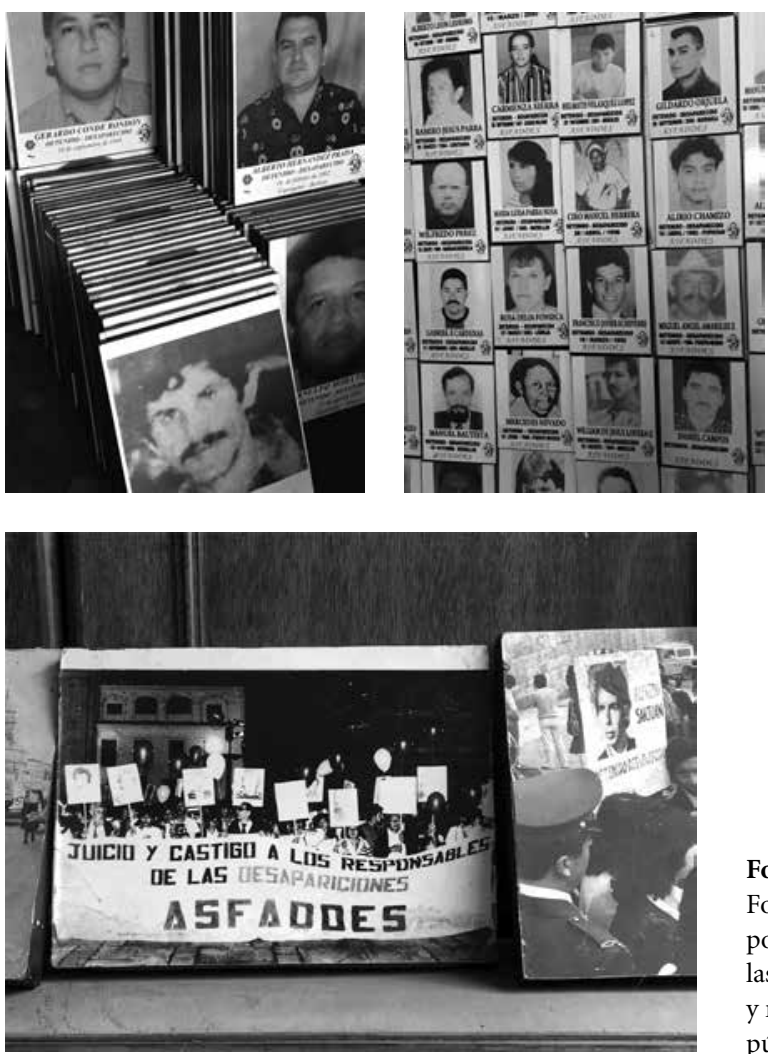

Fotografías 1, 2 y 3. Fotografías utilizadas por ASFADDES en las conmemoraciones y movilizaciones públicas, Bogotá 2019. 
Otra forma se advierte a partir de las prendas de vestir o artefactos personales de personas desaparecidas que pueden servir como vehículos para su búsqueda, identificación médico-legal y reconocimiento social (Guglielmucci, 2017). Por ejemplo, en las diligencias de exhumación realizadas por la Fiscalía General de la Nación de Colombia en más de 4.700 fosas encontradas en todo el país, los forenses no solo han desenterrado los restos corporales de personas desaparecidas sino también prendas, alhajas, zapatos, etc. Estos objetos que las víctimas llevaban cuando las asesinaron han sido empleados por los investigadores como un método útil para identificarlas. Las fotografías de las prendas de vestir y objetos personales hallados, preservados y registrados, son presentados periódicamente por la Unidad de Justicia y Paz de la Fiscalía en la revista Rastros y en su página web, en donde los familiares pueden hacer averiguaciones de lo que se ha encontrado en todas las regiones del país con el fin de reconocer alguno de ellos como distintivo de la persona buscada.

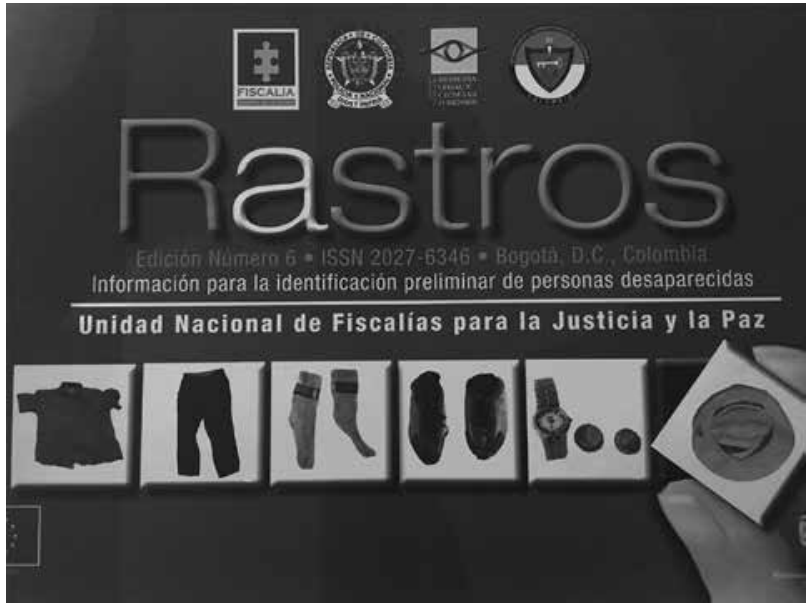

Fotografía 4.

Revista Rastros,

Fiscalía General de la Nación,

Colombia.

A su vez, los objetos y prendas de vestir de las personas desaparecidas, conservados por los familiares o allegados, pueden ser utilizados como insumo para obras de arte, exposiciones o intervenciones artísticas en la escena pública (plazas, museos, memoriales, centros culturales), que buscan ampliar la dimensión colectiva de estas ausencias. Esto se observa, por ejemplo, en el trabajo de las artistas colombianas Erika Diettes (como Relicarios) y Doris Salcedo (como Sin título y Atrabiliarios), donde ambas utilizan objetos personales de quienes han sido desaparecidos para la composición de sus respectivas obras de arte. A través de estos distintos usos y formas de circulación y exposición, las posesiones personales de las personas desaparecidas transcienden la esfera de lo íntimo (o de la reproducción de los lazos domésticos y la herencia familiar) para instalarse como: vehículos 
de denuncia o reclamo político, medios para la posible identificación y reconocimiento posmortem, u objetos musealizados que archivan y al mismo tiempo materializan la huella de las ausencias forzadas y los duelos suspendidos en un grupo o una comunidad más amplios.

Los objetos que pertenecieron a personas desaparecidas suelen ser así preservados y, al mismo tiempo, pasar a formar parte de procesos de manipulación, circulación y exposición que los apartan de su uso acostumbrado y los consagran como "posesiones inalienables" (Weiner, 1992). Es decir, por fuera del toma y daca cotidiano que caracteriza a los objeto-mercancía, supuestos reproductores del lazo social por medio del consumo. A través de su conservación y colocación en un nuevo contexto de uso y, de su exhibición restringida y estetizada (en tanto insumo de denuncia pública, vehículo para el reconocimiento forense o, dispositivo estético que expone la huella material de la ausencia), tales objetos son apartados de su utilidad acostumbrada y su rutina previa e, incluso, separados momentáneamente de dispositivos domésticos de archivo (cajas de fotos, armarios, cajones, altares, etc.). Ellos pasan a formar parte de nuevos repositorios y repertorios, ya sea en el campo del activismo político, la justicia o el arte. Y, de este modo, adquieren un nuevo valor de uso por medio de su conservación y su inscripción en novedosas formas de manipulación, circulación y publicidad controlada.

\section{Objetos supervivientes: vestigios de ausencias-presentes}

Las posesiones inalienables, según la antropóloga Annette Weiner, son objetos "imbuidos de las identidades intrínsecas e inefables de sus dueños... [y] conservadas por ellos de generación en generación dentro del contexto cerrado de la familia, el grupo de descendencia o dinastía" (1992, p. 6). Un objeto de este tipo, "puede afirmar rango, autoridad, poder o incluso dominio divino, porque se erige simbólicamente como representativo de los orígenes históricos o míticos de un grupo" (1992, p. 51). En este sentido, para la autora, el valor de estos objetos estaría dado por su conexión con el pasado colectivo y con la fundamentación y legitimación de la perpetuación y reproducción de la desigualdad a través del tiempo, por medio de la capacidad de producirlos, mantenerlos y retenerlos. Es decir, ellos no tienen un valor intrínseco, sino que este es dotado por su "autenticación cosmológica" o autenticidad, sus orígenes sagrados que impregnan su existencia única en el presente, en definitiva, su exclusividad.

El trabajo de campo de Weiner en Melanesia introdujo en sus estudios una consideración de género novedosa para su época, al describir y analizar el rol de las mujeres no solo en la dinámica del intercambio sino de la preservación y retención de objetos, lo que resultaba central en la reproducción de los grupos y las relaciones de estatus entre ellos. Salvando las distancias históricas, empíricas y epistemológicas entre el trabajo de campo de Weiner en las Islas Trobriand (Oceanía) y el problema aquí estudiado, lo que nos interesa rescatar de su planteo es la conexión entre el valor de un objeto con su posesión, circulación restringida y la consolidación de legados y memorias colectivas. Es decir, cómo los objetos son imbuidos de valor no tanto por su costo de producción, utilidad, originalidad o, su 
rol en una cadena de intercambios (ya sea como don o mercancía), sino más bien por los sentidos que se le atribuyen a través de su retención en un grupo o colectivo delimitado y la entrega o circulación restringida que permiten ampliar y mantener relaciones de exclusividad y simultáneamente de familiaridad. Esto último nos remite al problema de la configuración de comunidades morales, en nuestro caso, entrelazadas y fortalecidas a través de la circulación de objetos ligados a las personas desaparecidas y al sufrimiento de los supérstites ocasionado por la ausencia forzada.

En el caso aquí analizado, se trata de objetos que en el ámbito doméstico o de uso cotidiano suelen ser asociados simbólicamente a las personas y grupos que los poseen y con una historia familiar circunscrita. Objetos imbuidos de las características personales y hereditarias de sus usuarios que, a través de la separación de su utilidad acostumbrada y la asignación de nuevos usos en otras esferas de actividad y conocimiento, pueden llegar a ser considerados como posesiones inalienables, en tanto vestigio, rastro personal y resto físico de la ausencia de su poseedor. En este sentido, el carácter excepcional y exclusivo de estos objetos en tanto cuasi reliquias y vehículos de memoria estaría dado por la supuesta absorción en la materia de alguna de las cualidades de su poseedor y su colectivo de afinidad y pertenencia. Es decir, por su relación de contigüidad física y supervivencia material respecto a su dueño, y por el poder de estos objetos de funcionar como indicio, signo y atributo de la persona ausente.

El objeto antes poseído, al que se le quitó la posibilidad de volver a ser usado por su dueño, pasa así a marcar lo definitivamente inalienable en tanto propiedad: la huella de una existencia o de una vida que ha sido vivida y subjetivada a pesar de la tentativa de ser borrada. Y, de manera paralela, adquiere unos usos y formas de circulación y exposición impensados con anterioridad a la desaparición de su poseedor. La foto de la persona desaparecida es extraída del álbum u otro tipo de repositorio familiar y es publicitada a través de distintos medios como una forma no solo de identificación o reconocimiento interpersonal, sino como huella dejada por su ausencia en un grupo o colectivo más amplio y como un vehículo de denuncia política.

El valor de un objeto, en este sentido, no es intrínseco a él -como afirmara Weiner-. El valor es entendido como "relación significante, tomando a los modos de circulación o intercambio como algunas de las tantas prácticas [...] que pueden darle origen" (Nielsen, 2016, p. 401). En este caso, estos objetos tienen el valor de encarnar a los ausentes (en tanto huella material o vestigio de su existencia) e, incluso, hablar por la ausencia que ellos dejaron en sus grupos y redes de pertenencia. Algunos de estos objetos (como las imágenes de las personas desaparecidas) podrán replicarse mil veces, otros (como sus prendas o pertenencias personales) serán irreproducibles por el desgate característico grabado en ellos por su antiguos dueños, pero es su conservación y circulación como supervivencia de la existencia de su poseedor lo que permite comprender su valor y su rol como agentes materiales en la construcción de procesos sociales y políticos de memoria a través de quienes los conservan.

Es así como algunos objetos personales poseídos por personas desaparecidas, a través de su conservación, circulación y exposición circunscrita a ciertos campos de actividad como objeto-vestigio, cuasi reliquia y vehículo de memoria, permiten "retener mientras se da" y hacer familiares (relatives) o introducir en una misma comunidad moral a los no parien- 
tes. Pues, si bien la mayoría de las pertenencias de los desaparecidos no suelen intercambiarse en tanto se retienen en altares o archivos familiares y solo le serán transmitidas a sus deudos directos, algunas otras se prestan o donan para su exposición, intervención estética o, incluso, su reproducción mecánica, como ocurre con los retratos fotográficos.

\section{El vestigio personal como vehículo de producción de familiaridad}

Para ejemplificar algunas de las cuestiones planteadas con anterioridad nos referiremos a dos situaciones particulares que nos permiten analizar de qué manera la conservación así como la circulación y exhibición restringida de ciertos objetos permiten en Occidente ampliar o incluso construir relaciones de familiaridad con las personas desaparecidas, a pesar de no tener un vínculo biológico o de parentesco directo. Una, refiere a la usual reproducción y exhibición de las fotografías de personas desaparecidas utilizadas como una manera de denuncia política en distintos países de Latinoamérica en los que se han cometido graves violaciones a los derechos humanos (como Argentina, Chile, Colombia, México, Perú, entre otros). Otra, remite a la entrega de cajas que contienen testimonios y objetos personales de los desaparecidos y de sus familiares a los jóvenes que fueron apropiados de manera ilegal en el contexto del terrorismo de Estado en la Argentina y que, al ser localizados e identificados por la organización de derechos humanos (DDHH) Abuelas de Plaza de Mayo se reencuentran con su familia biológica, a través de un proceso que incluye distintas instancias de interacción e intercambio social, de manera paralela a la acción jurídica ligada a la garantía del derecho a la identidad.

En el primer caso, puede observarse no solo la conservación sino también la circulación y exposición restringida de ciertos objetos como las fotografías de las personas desaparecidas, a través de movilizaciones o conmemoraciones que exhortan su aparición con vida o, la búsqueda y restitución de sus cuerpos. Desde la Argentina hasta Colombia, incluyendo a la mayoría de los países de América latina, es común encontrar este tipo de actividad que, al mismo tiempo que mantiene vivo el recuerdo de las personas desaparecidas a través de la perdurabilidad de su imagen en la escena pública (ya sea a través de fotografías, audiovisuales, dibujos o grabados), habilita su reproducción para ampliar la relación de familiaridad (entendida como generadora de lazos de compromiso y responsabilidad), a través de objetos considerados personales o parte de repertorios íntimos.

En el segundo caso, a través de la búsqueda, recopilación, conservación y entrega de objetos que pertenecieron a los familiares desaparecidos, la organización Abuelas de Plaza de Mayo procura la restitución de lazos coartados de parentesco (entendiendo a la familia en un sentido fundamentalmente biológico), a través de un legado material. Al mismo tiempo que, desde el Estado, se renueva la identificación jurídica del joven que fue separado de su familia biológica a partir de su apropiación ilegal. La restitución de este legado parental, considerado originario o natural por parte de quienes buscaban a los jóvenes apropiados, y al mismo tiempo extraño o foráneo por quien desconocía su identidad biológica (a raíz de la desaparición forzada de sus progenitores), se da a través de vestigios materiales que fundamentan una familiaridad histórica compartida, aunque desconocida y difícil de asi- 
milar. Es la investigación, la preservación, la creación de una colección y la entrega de tales objetos, comprendidos como reliquias familiares lo que permite reconstruir y al mismo tiempo representar y simbolizar lazos de familia impedidos debido a la violencia terrorista por parte del Estado. Tales objetos, en la narrativa y performance de restitución de la identidad biológica por parte de Abuelas, funcionan como el testamento y prueba material de un lazo de parentesco biológico preexistente, no consumado debido a la imposibilidad de la crianza en su verdadera familia. En palabras de su presidenta, Estela de Carlotto:

Estos actos de entrega del Archivo Biográfico Familiar son de mucha alegría y emoción. El Archivo nació cuando nos dimos cuenta de que no era tan fácil encontrar a los nietos que estábamos buscando y que las familias que los buscaban, sobre todo los abuelos, ya no iban estando bien de salud o iban falleciendo. La idea de crear este Archivo fue que cada nieto, a medida que lo fuéramos encontrando, pudiera encontrarse con parte de la familia que reconstruyó la historia de su papá y mamá para que todos conozcan de dónde vienen, quiénes son ${ }^{1}$.

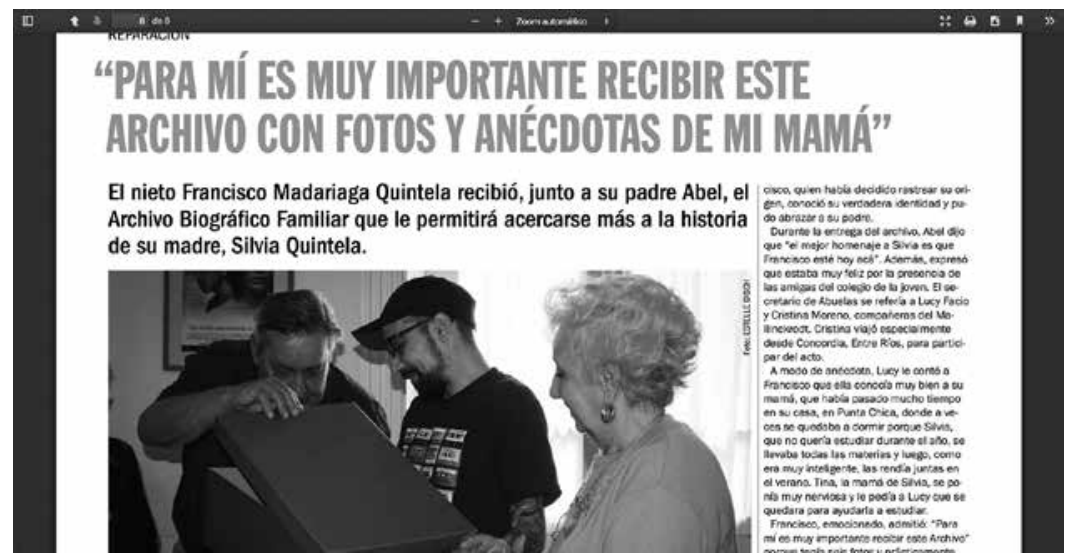

Fotografía 5. "El nieto Francisco Madariaga Quintela recibió, junto a su padre Abel, el Archivo Biográfico Familiar que le permitirá acercarse más a la historia de su madre, Silvia Quintela”. Autoría de Estelle Disch, en Publicación de las Abuelas de Plaza de Mayo. Por la identidad, la memoria y la justicia, XVI (166), Octubre de 2017.

Salvando todas las discusiones que esto plantea para los estudios sobre violaciones a los derechos humanos, parentesco e identidad (Gandsman, 2009), lo que nos interesa destacar aquí es el rol que estos objetos -entendidos como posesiones inalienables- juegan en 
la producción o reproducción de lazos de parentesco y familiaridad. O, en el modo en que ellos dan carnadura material a una identificación parental que se suele sustentar en un análisis de $\mathrm{ADN}$, el parecido físico entre progenitores y sus descendencias, o la reconstrucción documental de la apropiación ilegal. La caja con objetos personales pertenecientes a los predecesores $\mathrm{u}$ otros miembros de la familia desaparecidos o fallecidos, seleccionados y entregados por la institución, forma parte del proceso ritual de anexión de una vieja/ nueva identidad para un mismo sujeto dividido entre al menos dos legados familiares (el que posee un fundamento político-biológico y el que se basa en la crianza y la apropiación clandestina). De este modo, a través de tales objetos supervivientes, se plasma no solo una nueva identidad personal (comprendida por Abuelas como la auténtica) sino un legado familiar que fue transmitido entre generaciones y que se supone que continuará a través de su conservación y retransmisión, a pesar de haber sido duramente violentado y potencialmente suprimido a partir de la desaparición de varios de sus miembros.

\section{El arte de los objetos que marcan ausencias}

Otra forma en que los objetos de personas desaparecidas son conservados y al mismo tiempo circulados y expuestos son las obras de arte. En este texto nos referiremos a la obra Relicarios de la artista colombiana contemporánea Erika Diettes, quien desde hace más de 10 años trabaja alrededor de las experiencias de víctimas del conflicto armado en Colombia a través de fotografías y objetos pertenecientes a ellos.

En Relicarios (2011-2015), la artista conserva objetos que le fueron entregados por parientes de personas desaparecidas a partir del establecimiento de una relación interpersonal de confianza mutua (a partir de grupos de apoyo psicosocial) y que representan lo más preciado para ellos en tanto vestigios asociados a recuerdos familiares. Su selección y reunión en una especie de cofre de vidrio tenuemente iluminado, en cuyo interior hay una caja traslucida elaborada con resina color sepia, transmite la sensación de estar en un espacio y ante un objeto sagrado: una reliquia. Ya sea porque el objeto allí conservado fue lo último que tocó la persona desaparecida o porque era su posesión favorita. La disposición alineada entre cada cofre, a una altura poco elevada del piso, recuerda las tumbas de un cementerio, ante las cuales el visitante debe inclinarse o agacharse para poder observar su contenido, en una postura de persignación u ofrenda. Esta forma de reunión, tratamiento y exposición museográfica los expone como objetos de veneración y duelo por parte de quienes han sufrido esa pérdida pero, también dimensiona en su conjunto el carácter colectivo de la pérdida y el dolor a través de la experiencia sensitiva del recogimiento. 


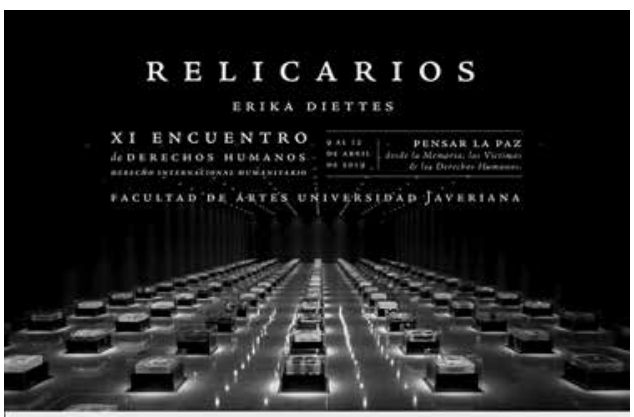

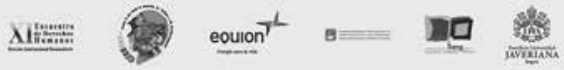
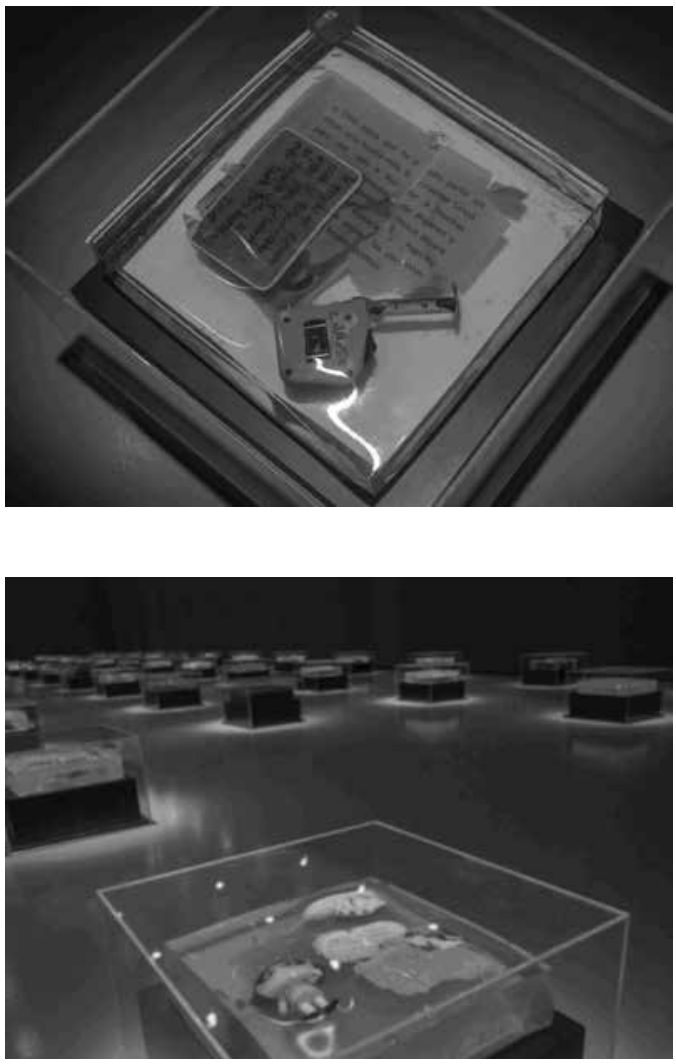

Fotografías 6, 7, 8, 9

y 10. Archivo Obra

Relicarios, Erika

Diettes. Fuentes:

https://www.utadeo. edu.co/es/noticia/ especiales/home/1/ relicarios https://facartes. uniandes.edu.co/ evento/exposicionrelicarios-de-erikadiettes/
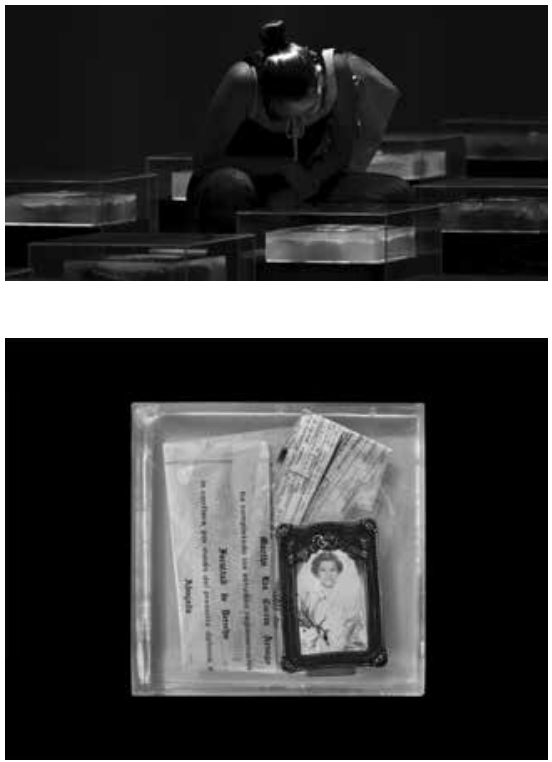
La artista que recibe estos objetos devuelve, a su vez, una fotografía de cada relicario a los donantes de estos objetos. De tal manera, los familiares o allegados reciben un producto transformado por ella como una forma de agradecimiento hacia sus testimonios y lo que estos representan, así como respecto a su difícil trabajo de duelo en Colombia, donde los perpetradores no han reconocido la responsabilidad de sus acciones y las víctimas no ha obtenido una condolencia pública (Rubiano Pinilla, 2018).

Este es un caso, entre muchos otros (como el de Doris Salcedo o Juan Manuel Echavarría), donde los objetos entendidos como vestigio o, en este caso, reliquias de las personas desaparecidas son incorporados en obras artísticas que procuran invocarlas y dar cuerpo a su ausencia-presencia, a través de sus huellas materiales (prendas de vestir, objetos de uso diario, fotografías, etc. $)^{2}$.

En este tipo de obras, los objetos que pertenecieron a víctimas de desaparición forzada hacen parte del reconocimiento simbólico de la necesidad de hacer un proceso de duelo familiar y colectivo. Montados en espacios que se asemejan a cementerios o templos, a falta de una tumba donde realizar el ritual de duelo, ellos se establecen como metáfora de este vacío o imposibilidad de condolencia colectiva. Pertenencias que, comprendidas como posesiones inalienables, dan la posibilidad de materializar la ausencia y reconocer -en una dimensión colectiva y pública- que estas pérdidas efectivamente ocurrieron a pesar de la falta de un cuerpo. La simbolización de la pérdida, a través de la disposición de estos objetos poseídos por las personas desaparecidas, certifican de algún modo la ausencia (ante la falta de otro tipo de evidencias como incluso el certificado de defunción o la confesión del perpetrador), dimensionan el peso de la pérdida, y facilitan la construcción de lazos de familiaridad y solidaridad más amplios con los desaparecidos y quienes los buscan.

\section{A modo de conclusión}

Tal como lo advirtió tempranamente Annette Weiner (1976), la literatura antropológica clásica sobre el rol del intercambio en la construcción del lazo social (la obra de Marcel Mauss, Bronislaw Malinowski, entre otros) se enfocó en la circulación de objetos en lo que se consideraba la esfera pública y masculina de la distribución, siendo poco estudiada la producción y su efecto en la reproducción de las relaciones de estatus y desigualdad entre familias y otros grupos sociales a través de la conservación y no-circulación de ciertos bienes, asociada a la esfera de actividad considerada doméstica y femenina. Fue Weiner quien destacó el rol protagónico de las mujeres en la economía y organización social trobriandesa y su poder en la producción y reproducción de las relaciones jerárquicas entre grupos a través de las posesiones inalienables, consideradas intrínsecas al estatus de sus dueños. Las situaciones sociales abordadas en este texto, distan de las preocupaciones y el campo de estudio de Weiner, sin embargo sus observaciones han servido de inspiración para preguntarnos sobre el rol y el valor de aquellas posesiones que se consideran como intrínsecas o exclusivas respecto a la identidad de una persona o grupo y que son conservadas en redes parentales a modo de reliquia. Pero que, de manera simultánea, circulan de un modo restringido y se exponen o publicitan de una manera (extra) ordinaria o esteti- 
zada (no necesariamente espectacularizada). Posesiones que, paradójicamente, permiten retener mientras se da, se presta o se transfiere de manera circunscrita (como las cajas de Abuelas), pudiendo reforzar al grupo poseedor al mismo tiempo que permiten ampliar las relaciones de familiaridad y pertenencia.

En los casos aquí estudiados, los objetos, preservados, coleccionados y dispuestos en nuevos repertorios colectivos, configuran lo que algunos antropólogos y críticos de arte han concebido como comunidades de sufrimiento y duelo (Das, 2008; Diéguez, 2007 y 2013 ) 3 . Pues, atendiendo a lo que Renan (2000 [1882]) señalaba ya en el siglo XIX, en definitiva lo que define a una nación es el olvido compartido (o una memoria selectiva) y nuestros muertos, es decir, aquellos a quienes consideramos como ancestros o dolientes en común frente a otros que resultan excluidos de nuestro linaje e historia compartida como connacionales.

Hacer del dolor individual una experiencia colectiva es la premisa para pensar la posibilidad de una "comunidad moral". No obstante, si se supone que el sufrimiento -de modo general- nos induce al aislamiento, cabe preguntarse cómo trascender ese estado para intentar conformar -aunque sea efímeramente- un cuerpo en el que mi dolor pueda comunicarse con el dolor del otro. Por ello Veena Das se cuestiona lo siguiente: "si el dolor destruye la capacidad de comunicarse [...], ¿ cómo puede alguna vez trasladarse a la esfera de la articulación en público?” (2008, p. 431). Para responder este cuestionamiento, retoma un argumento de Wittgenstein quien considera que "la afirmación 'me duele' no es un enunciado declarativo que pretenda describir un estado mental, sino que es una queja" (Ibídem, p. 432), y esa acción de la queja, lejos de hacer el dolor "incomunicable", propicia un lugar de articulación colectiva.

Es justamente en la configuración de estas comunidades o communitas del dolor y de luto compartidos (con toda la carga política que supone esta actividad colectiva y pública), donde las mujeres y la producción femenina de los lazos comunes o de la familiaridad tienen un rol predominante. En gran parte, es a través de la conservación de los vestigios materiales que recuerdan a los ausentes, que se recrean y amplían los lazos sociales que los contienen. La circulación de fotos, objetos y vestimenta que testimonian la existencia de aquellos que lo han perdido todo, no solo la vida sino incluso el derecho a ser sujeto de duelo, permite que su rememoración sea posible y perdurable, reteniendo a los desaparecidos en la memoria y el legado de los vivos.

De este modo, a diferencia de lo que notaba Weiner en sus estudios empíricos, estas posesiones inalienables (por la pertenencia a sus dueños desaparecidos), en vez de producir y reproducir desigualdades y diferencias de estatus, parecieran tener el efecto contrario: el fomento de la configuración de una communitas (aunque solo sea una experiencia esporádica). Los recuerdos asociados a vestigios materiales de personas desaparecidas, que remiten al dolor provocado por su ausencia y por la falta de un cuerpo que permita realizar el duelo, parecieran no solo ampliar la familiaridad entre los dolientes sino suspender también por momentos las diferencias y desigualdades que existen en otras esferas de actividad que los caracterizan y definen. 


\section{Notas}

1. https://explicitoonline.com/abuelas-entrego-a-dos-nietas-recuperadas-en-mendozael-archivo-fotografico-de-sus-padres-desaparecidos/

2. Por ejemplo, las siguientes obras: "Rio Abajo" de Érika Diettes, "Atrabiliarios" (19921993) y "Plegaria muda" (2009-2010) de Doris Salcedo, y Réquiem NN, de Juan Manuel Echavarría, entre otras.

3. Ileana Diéguez asocia las conmemoraciones, marchas y actividades artísticas en torno a las personas desaparecidas como acciones fúnebres, luctuosas, actos de duelo público por todas las ausencias que pesan sobre nosotros. Estas nos permite reconocernos en tanto una comunidad moral, vislumbrada como communitas de dolor.

\section{Bibliografía}

Ortega, F. (Ed.) (2008). Veena Das: Sujetos del dolor, agentes de dignidad. Bogotá: Universidad Nacional de Colombia y Pontificia Universidad Javeriana.

Diéguez, I. (2013). Cuerpos sin duelo. Iconografías y teatralidades del dolor. Córdoba: Documenta/Escénicas.

Diéguez, I. (2007). Escenarios liminales. Teatralidades, performances y política. Buenos Aires: Atuel.

Gandsman, A. (2009). A Prick of a Needle Can Do No Harm: Compulsory Extraction of Blood in the Search for the Children of Argentina's Disappeared, en The Journal of Latin American and Caribbean Anthropology 14 (1): 162-184.

Guglielmucci, A. (2017). Identidades fragmentadas: los procesos de identificación forense en casos de desaparición forzada, en Avá. Revista de Antropología (30): 1-19.

Nielsen, A. (2016). Bajo el hechizo de los emblemas: políticas corporativas y tráfico interregional en los Andes Circumpuneños, en Aschero. C. et al (Ed.) Producción y circulación prehispánicas de bienes en el sur andino. Córdoba: Brujas.

Panizo, L. (2012). Ausencia y desaparición: el caso de los desaparecidos de la última dictadura militar en Argentina, en Argos 29 (57): 94-125.

Renan, E. (2000) [1882]. ¿Qué es una Nación? en Fernández Bravo, A. (ed.) La invención de la Nación. Buenos Aires: Manantial

Rubiano Pinilla, E. (2018). Duelo, memoria y dolor en la obra de Erika Dietes, en AURA. Revista de Historia y Teoría del Arte 7, 83-108.

Weiner, A. (1992). Inalienable Possessions. University of California Press: Berkeley.

Weiner, A. (1976). Women of Value, Men of Renown: New Perspectives in Trobriand Exchange. Austin: The University Press.

Abstract: Throughout my field work in Argentina and Colombia (2000-2020), I had the opportunity to record different situations in which objects that belonged to missing per- 
sons are safeguarded in multiple ways from the vicissitudes of time and oblivion. One of these ways of making them durable has been through domestic altars, forensic practices, public denunciation performances and artistic works. Such objects - understood as "inalienable possessions" (Weiner 1992)- acquire value through their preservation, archiving, and aesthetic display, rather than through exchange in a market or prestige economy. In this text, based on the description of different experiences, I analyze what are the practices aimed at preserving the existence of objects that have transcended the disappearance of their owners and the restricted ways of circulating or exposing them in certain situations or contexts in which they acquire novel meanings. This analysis allows us to see the way in which such objects become relics or traces of denied existence and, at the same time, in mediations for the political claim in public settings.

Keywords: Enforced disappearance - personal possessions - memory - collective mourning.

Resumo: Ao longo de meu trabalho de campo na Argentina e na Colômbia (2000-2020), tive a oportunidade de registrar diferentes situações em que objetos pertencentes a pessoas desaparecidas são salvaguardados de múltiplas maneiras das vicissitudes do tempo e do esquecimento. Uma dessas formas de torná-los duradouros tem sido por meio de altares domésticos, práticas forenses, performances de denúncia pública e obras artísticas. Tais objetos -entendidos como "bens inalienáveis" (Weiner 1992)- adquirem valor por meio de sua preservação, arquivamento e exibição estética, ao invés de troca em um mercado ou em circuitos de valor simbólico. Neste texto, a partir da descrição de diferentes experiências, analiso quais são as práticas que visam preservar a existência de objetos que transcenderam o desaparecimento de seus proprietários e as formas restritas de circulá-los ou expô-los em determinadas situações ou contextos em que adquirem significados novos. Essa análise permite ver a forma como tais objetos se tornam relíquias ou vestígios de existência negada e, ao mesmo tempo, em mediações para a reivindicação política em ambientes públicos.

Palavras chave: Desaparecimento forçado - bens pessoais - memória - luto coletivo.

[Las traducciones de los abstracts fueron supervisadas por el autor de cada artículo] 